\section{Çeşitli zayıf organik asitler ve kombinasyonlarının saccharomyces cerevisiae'ye karşı antifungal etkileri}

Özet

Zayıf organik asitlerin S. cerevisiae hücrelerine karşı antifungal etkinliği incelenmiştir. Zayıf organik asitler olarak, hekzanoik (C6), oktanoik (C8), dekanoik (C10) ve benzoik asitlerin Minimum İnhibitör Konsantrasyon (MIK) ve inhibisyon bölgesi ölçümleri ile belirlenmiştir. MİK sonuçlarına göre maya hücrelerine karşı en etkili asit, dekanoik asittir (MİK: 0,2-0,3 $\mathrm{mM}$ ). Bahsi geçen zayıf asitlerin inhibisyon mekanizmalarını anlayabilmek için, ekstraselüler ortam pH ölçümleri yapılmıştır. Ekstraselüler pH'daki düşüş; pH'da aynı miktarda düşüşe neden olan hidroklorik asit $(\mathrm{HCl})$ ile karşılaştırılmıştır. Sonuçlar, maya hücrelerine karşı zayıf asitlerin etkinliklerinin sadece asitlikten kaynaklı olmadığını, ancak anyonların toksik etkisi ve zayıf asitlerin hücresel membran içine sızmasının rol oynayabileceğini göstermiştir. Buna ek olarak, zayıf asitlerin sinerjik etkileri incelenmiş ve bu zayıf asitlerin kombinasyolarının tek başına kullanımlara göre daha etkili olduğu gözlemlenmiştir. Çalışmada, zayıf asitlerin antifungal aktivite mekanizmalarına genel olarak bir açıklama getirmekle birlikte farklı konsantrasyonlarda kombinasyon halinde kullanımları da incelenmiştir.

Anahtar kelimeler: Saccharomyces cerevisiae, Zayıf organik asitler, Antifungal aktivite, Kombinasyon.

\section{Antifungal activity of various weak organic acids and their combinations against saccharomyces cerevisiae}

\begin{abstract}
Antifungal activity of four weak organic acids against $S$. cerevisiae cells was examined. Antifungal effects of hexanoic (C6), octanoic (C8), decanoic (C10) and benzoic acids were determined through Minimum Inhibitory Concentration (MIC), and inhibition zone measurements. The most effective weak acid was decanoic acid (MIC: 0.2-0.3 mM) according to MIC results. In order to have some insight into the inhibition mechanism of these weak acids, their efficiency was compared with that of hydrochloric acid $(\mathrm{HCl})$ giving the same amount of drop in extracellular $\mathrm{pH}$. Results demonstrated that the inhibition of yeast cells by weak acids is not simply due to acidity, but toxic effect of the anion and the insertion of the weak acids inside the cellular membrane may play a role. Moreover, synergistic effects of weak acids were examined, and it has been shown that combinations of weak acids are more effective than using weak acids alone. Thus, this research not only opens new perspectives on antifungal activity mechanisms of weak acids but also help their usage in combination widely. Key Words: Saccharomyces cerevisiae, Weak organic acids, Antifungal activity, Combination.
\end{abstract}

\section{Giriş}

Zayıf organik asitler, yiyecek içecek endüstrisinde Saccharomyces cerevisiae dahil olmak üzere birçok mayaya karşı koruyucu olarak yaygın şekilde kullanılmaktadır (Lambert ve Stratford, 1999; Mollapour vd., 2006; Papadimitriou vd., 2007; Ullah vd., 2012). Yanlış ve aşırı kullanımlara bağlı olarak, maya suşları bu koruyuculara karşı dirençli hale gelebilmektedir. $\mathrm{Bu}$ nedenle zayıf asitlerin daha etkin kullanımının sağlanması için maya hücrelerini inhibe edici mekanizmalarının temelini anlamak gerekmektedir.

\section{Araştırma Makalesi}

\section{Hatice Büşra KONUK Bengü ERGÜDEN}

Gebze Teknik Üniversitesi, Mühendislik Fakültesi, Biyomühendislik Bölümü, Kocaeli

İlgili yazar

(Corresponding Author)

Bengü Ergüden

Gebze Teknik Üniversitesi, Mühendislik

Fakültesi, Biyomühendislik Bölümü,

Gebze, 41400, Kocaeli

*b.sezen@gtu.edu.tr

Makale Bilgisi

Geliș: 07-08-2018

Kabul: 03-12-2018

https://dx.doi.org/10.31797/vetbio.451505

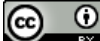

This work is licensed under a Creative Commons Attribution 4.0 International

License

Konuk, H.B., Ergüden, B. (2018). Çeşitli zayıf organik asitler ve kombinasyonlarının saccharomyces cerevisiae'ye karşı antifungal etkileri J Adv VetBio Sci Tech. 3(3): 28-34. DOI: 10.31797/vetbio.451505 
Yağ asitleri (hekzanoik/kaproik, oktanoik/kaprilik, dekanoik/kaprik) bir ucunda karboksil grubu (-COOH) ve diğer ucunda ise metil grubu (-CH3) yer alan karboksilik asitlerdir. Oktanoik ve dekanoik asit, endüstriyel üretimde mayaların alkol fermantasyonu sırasında ortaya çıkan fermantasyon inhibitörleridir (Legras vd., 2011).

Organik yağ asitlerinin $S$. cerevisiae hücrelerine karşı antifungal etkisi çeşitli çalışmalarda gösterilmiştir (Bergsson vd, 2001; Cabral vd., 2001; Kumar vd., 2011). Orta ve kisa zincirli yağ asitlerinin toksisitesi lipofilik özellikleriyle ilişkilidir (Tenreiro vd., 2002). $\mathrm{Bu}$ zayıf asitler, pasif difüzyon ile plazma zarını geçer ve lipofilik formlarına daha yüksek iç $\mathrm{pH}$ değerinde nötr sitoplazmada ayrışabilir ve bu durum hücre içi $\mathrm{pH}^{\prime}$ in düşmesine ve toksik anyon birikimine neden olabilir (Viegas ve Sá-Correia, 1997; Cabral vd., 2001; Legras vd., 2011). Zayıf organik asitlerin mayalara karşı etki mekanizmalarının anlaşılması yiyecek ve içecek endüstrisi başta olmak üzere birçok sahada, etkin kullanımların ve verimliliğin arttırılması için büyük bir öneme sahiptir. Bu çalışmada, hekzanoik, oktanoik, dekanoik ve benzoik aside ve bunların kombinasyonlarına maya hücrelerinin cevabı incelenmiş ve bu zayıf organik asitlerin maya membranlarında oluşturdukları etkiler araştırılmıştır. Olas1 membrana bağlı etkiler ve maya hücrelerinin inhibisyonunun sadece asiditeden kaynaklanmadığ gösterilmiştir.

\section{Materyal ve metot}

\section{Minimum inhibisyon konsantrasyonu (MIKK) ölçümü}

S. cerevisiae YPH499 suşu, bir gün boyunca $25^{\circ} \mathrm{C}^{\prime} \mathrm{de}$, maya ekstraktı, pepton ve glikoz ile hazırlanan (yeast extract peptone glucose, YPD, HIMEDIA) besiyeri içinde kültürlenmiştir. Test suşu, nihai yoğunluk $1 \mathrm{x}$ $10^{6} \mathrm{CFU} / \mathrm{mL}$ olacak şekilde YPD besiyerinde süspanse edilerek seyreltilir (Kumar vd., 2014). Dimetil sülfoksit (DMSO) içerisinde çözülmüş olan zayıf asitler, 24 kuyucuklu mikrotitrasyon plakasında belirlenen konsantrasyonlarda hazırlanır. Daha sonra plakanın her kuyucuğuna $S$. cerevisiae hücreleri ilave edilir. Plakalar çalkalanmak suretiyle $25^{\circ} \mathrm{C}^{\prime} \mathrm{de} 48$ saat inkübe edilir. İnkübasyondan sonra, MİK değerleri, görünür herhangi bir maya büyümesinin olmadığ en düşük konsantrasyon olarak ifade edilir (Bracey vd., 1998; Holyoak vd., 1999).

\section{İnhibisyon zon ölçümü}

YPH499 suşuna karşı zayıf asitlerin antifungal aktiviteleri, standart agar difüzyon metodu kullanılarak belirlenmiştir (Bauer vd., 1966; Rattanachaikunsopon ve Phumkhachorn, 2010). Bu yöntemde, $500 \mathrm{uL}$ YPH499 taze kültürü YPD katı besiyerinin olduğu plaklara yayılır. Her plağa $5 \mathrm{~mm}$ çaplı kuyucuklar aç1lır. Zayıf asitler, DMSO içinde \%10 konsantrasyona seyreltilerek hazırlanır ve $55 \mathrm{uL}$ asit kuyucuklara doldurulur. Plaklar, $25^{\circ} \mathrm{C}^{\prime}$ de 48 saat inkübe edilir. İnkübasyondan sonra, inhibisyon zonlarının çapları santimetre cinsinde ölçülür.

\section{Hücre dışı pH ölçümü}

YPH499 suşu $20 \mathrm{~mL}$ YPD besiyerinde $25^{\circ} \mathrm{C}^{\prime}$ de gece boyunca inkube edilir. İnkübasyondan sonra, maya hücreleri 5 dakika boyunca 3200 rpm'de santrifüj edilir. Süpernatant ortamdan uzaklaştırılarak pellet elde edilir. Pellet $\mathrm{dH}_{2} \mathrm{O}$ ile iki kez y1kanır. Sterilize edilmiş olan pellet dH20 içinde süspansiyon haline getirilir. Her deney için yaklaşık $50 \mathrm{mg}$ yaş ağırlıklı maya hücresi (pellet) kullanılmıştır (Gášková vd., 2013; Wang vd., 2015). DMSO içerisinde çözülerek hazırlanan zayıf asitler ve kombinasyonları, tekrar süspansiyon haline getirilen maya hücrelerine ilave edilir. Araştırılmak istenen nihai konsantrasyonlara $\% 2$ glikoz (0. dakikada) ve zayıf asitler (18. dakika) manuel olarak enjekte edilir. Ekstraselüler $\mathrm{pH}$, belirtilen zamanlarda, pH metre ile ölçülerek kaydedilir (HANNA, USA).

\section{İstatistiksel analiz}

MİK değerleri, inhibisyon çapı ölçümleri, hücre dışı pH ölçümleri her zayıf asit için en az 3 kez tekrarlanmıştır. Tüm deney gruplarının ortalamaları hesaplanıp, standart sapmalar Microsoft Excel kullanılarak belirlenmiştir.

\section{Bulgular ve tartışma}

Maya ve mantarların kontrolsüz olarak çoğalmaları, bozulmalara neden olmaları, gıda endüstrisi başta olmak üzere tıbbi alan ve diğer alanlar için kritik bir 
sorundur. S. cerevisiae, gidalardaki bozulmalara neden olabilir ve zayıf asitlere karşı direnç kazanabilir. $\mathrm{Bu}$ mekanizma taşıyıcı bir protein olan ve zayıf asitlerin aktif sızıntısına neden olan ABC'nin (ATP bağlayıcı kaskat), Pdr12p, ekspresyonunun artmasiyla gerçekleşmektedir (Holyoak vd., 1999; Hatzixanthis vd., 2003; Mollapour vd., 2006).

Sunulan çalışmada literatürün kapsamlı bir şekilde araştırılmasından sonra, $S$. cerevisiae 'ya karşı, belirtilen dört zayıf organik asidin MíK ve inhibisyon zon ölçümü testi kullanılarak antifungal aktiviteleri hakkındaki bilgilerin sınırlı olduğu görülmüştür. Daha da önemlisi, literatürde bildirilen deneysel veriler, farklı deneysel koşullarla ortaya konulduğu için verilerin birbirleriyle kıyaslanması ve buradan yola çıkarak zayıf asitlerin ve bunların kombinasyonlarının antifungal etkinlikleri hakkında yorum yapmak oldukça zorlaşmaktadır. $\mathrm{Bu}$ nedenle, çalışmanın başında, ilk olarak zayıf asitlerin antifungal etkinliğinin bir ölçüsü olarak MíK ve inhibisyon zonu değerleri tespit edilmiştir (Tablo 1).

Tablo 1. Zayıf asitlerin antifungal aktivitesi inhibisyon zon ölçümü ve MiK değerleri olarak sunulmuştur. Çözünürlüğü artırmak için zayıf asitler DMSO ile karıştırılmıştır.

Table 1. Antifungal activity of weak acids presented as zones of inhibition and MIC values. Weak acids were mixed with DMSO to increase solubility.

\begin{tabular}{|c|c|c|c|}
\hline \# & Zayıf asitler & İnhibisyonu zon çapı $(\mathrm{cm}) *$ & MİK (mM) \\
\hline 1 & Hekzanoik asit & $3,3 \pm 0,3$ & $4,0-8,0$ \\
\hline 2 & Oktanoik asit & $2,7 \pm 0,2$ & $1,5-2,5$ \\
\hline 3 & Dekanoik asit & $2,9 \pm 0,3$ & $0,2-0,3$ \\
\hline 4 & Benzoik asit & $2,0 \pm 0,2$ & $4,0-8,0$ \\
\hline
\end{tabular}

MíK sonuçlarına göre, dekanoik asit $(0,2-0,3 \mathrm{mM})$ oktanoik ve diğer asitlere göre maya hücreleri üzerine daha toksik bir etkiye sahiptir. Bunun aksine, hekzanoik asit $(3,27 \pm 0,3)$ ise inhibisyon zon ölçümlerine göre diğer asitlere göre en etkin kimyasal olarak gözlemlenmiştir. Elde edilen bulgular daha önceki yıllarda yapılan çalışmaları da desteklemektedir (Jarboe vd., 1989; Viegas ve Sá-Correia, 1997). Dekanoik asitin oktanoik asite göre lipofilik özelliğinin yüksek olmasına bağlı olarak hücre geçirgenliğini daha fazla arttırdığı ve bu sayede daha yüksek antifungal etkiye sahip olduğu ifade edilmiştir (Viegas vd., 1989; Bergsson vd, 2001; Kumar vd., 2014).

Antifungal etki tespit edildikten sonra, zayıf organik asitlerin farklı konsantrasyonlarının hücre dış1 ortamdaki $\mathrm{pH}$ değişimini nasıl etkilediği incelenmiştir. Hücre dışı pH değişimi, zayıf asitlerin membran geçirgenliğini değiştirmesi ile membran yapısındaki bozulmaya işaret etmektedir. Hekzanoik, oktanoik, dekanoik ve benzoik asitlerin farklı konsantrasyonlarının maya hücrelerinde membran yapısını etkileyerek oluşturdukları hasar, ekstrasellüler ortam pH değişimlerinin ölçülmesi ile Şekil 1' de ifade edilmiştir.

Organik asitlerin maya süspansiyonuna eklenmesi Şekil 1'de de görüldüğü gibi hücre dışı $\mathrm{pH}$ ' da ani bir düşüşe neden olmaktadır (Şekil 1). Maya hücreleri, aynı $\mathrm{pH}$ düşüşünü sağlamak için, bu düşüşe neden olabilecek uygun $\mathrm{HCl}$ konsantrasyonlar1 $\left(10^{-3} \mathrm{M}^{\prime}\right.$ a kadar) ile muamele edilmiştir (Şekil 2) ve bu hücrelerin yaşamaya devam ettiği gözlemlenmiştir (Tablo 2). $\mathrm{Bu}$ durum, zayıf asitlerin antifungal etkinliğinin sadece asitlikleri yoluyla olmadığını; lipofilik özellikleri ile hücre membran geçirgenliğini arttırarak anyonik kısımlarının da etkili olduğunu göstermiştir. 
a)

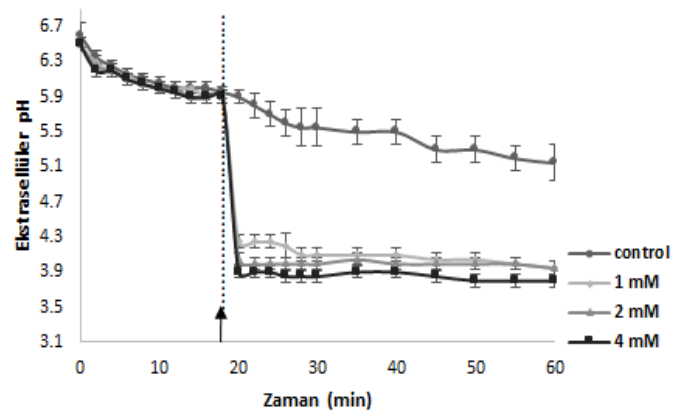

c)

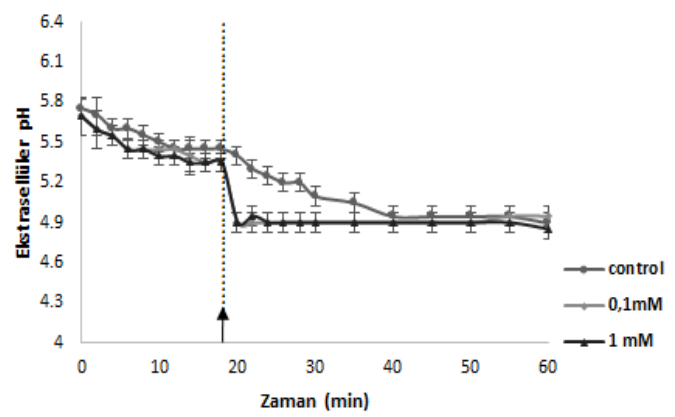

b) Oktanoik Asit

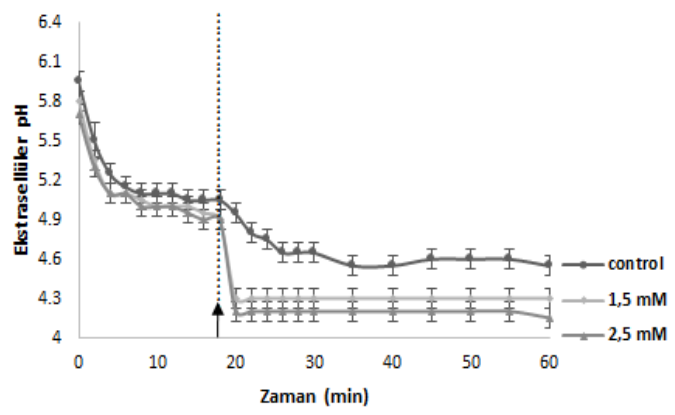

d)

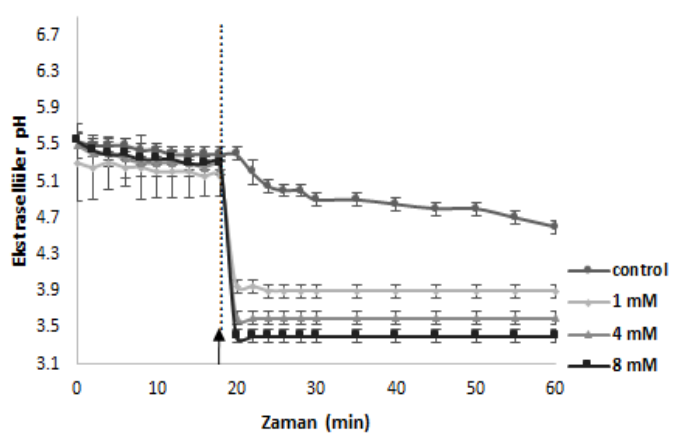

Şekil 1. Glikozla uyarılan ortamda zayıf asitlerin S. cerevisiae'nın hücre dışı pH'ına etkisi. Oklar, a) hekzanoik asit, b) oktanoik asit, c) dekanoik asit ve d) benzoik asidin hücre süspansiyonuna eklenme zamanını gösterir.

Figure 1. Effects of weak acids on extracellular $\mathrm{pH}$ of $S$ cerevisiae in glucose-induced medium. The arrows indicate the time of addition of a) hexanoic acid, b) octanoic acid, c) decanoic acid and d) benzoic acid.)

\section{Hidroklorik Asit}

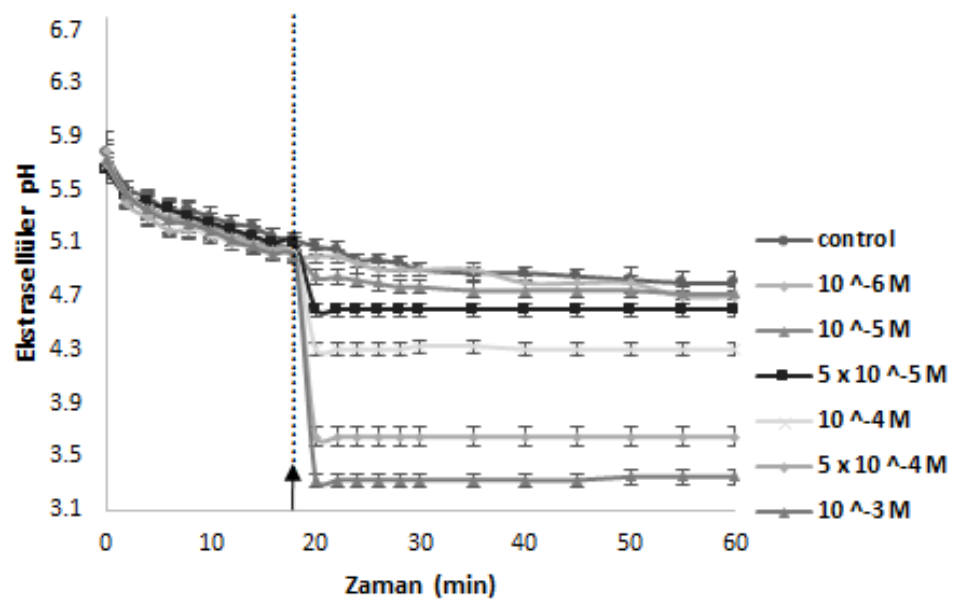

Şekil 2. Glikozla uyarılan ortamda $S$. cerevisiae' nın hücre dışı pH'ında zayıf asitlerle aynı pH düşüşünü sağlayan çeşitli konsantrasyonlardaki $\mathrm{HCl}$ etkisi. Oklar $\mathrm{HCl}$ ilavesinin zamanını göstermektedir.

Figure 2. Effects of $\mathrm{HCl}$ for various concentration which were provide the same $\mathrm{pH}$ drop with weak acids on extracellular $\mathrm{pH}$ of $\mathrm{S}$ cerevisiae in glucose-induced medium. The arrows indicate the time of addition of $\mathrm{HCl}$. 
Tablo 2. HCl'ye maruziyetten sonra S. cerevisiae hücrelerinin canlılığı, ND: belirlenemedi.

Table 2. Viability of $S$. cerevisiae cells upon exposure to $\mathrm{HCl}, N D$ : not determined.

\begin{tabular}{|c|c|c|c|}
\hline$\#$ & HCl konsantrasyonu (M) & Hücre canlılı̆̆ & Son ekstrasellüler $\mathbf{p H}$ \\
\hline 1 & $10^{-4}$ & + & 4,30 \\
\hline 2 & $10^{-3}$ & + & 3,35 \\
\hline 3 & $10^{-2}$ & + & ND \\
\hline 4 & $10^{-1}$ & - & ND \\
\hline
\end{tabular}

Zayif organik asitlerin antifungal etkinlikleri lipofilik özelliklerinden dolayı hücre zarını bozmaları ve geçirgenliği arttırmaları ile ilişkili olabilir. Antifungal etki mekanizmalarının bilinmesi özellikle g1da ve meyve suyu sanayisinde önemli rolü olan maya hücrelerinin etkinliğinin azaltılması için önemli bir bilgi olacaktır.

Zayıf organik asitlerin kombinasyonlarının sinerjik etkilere sahip olup olmadığı da sunulan çalışmada oluşturulan kombinasyonların test edilmesi ile incelenmiştir. Elde edilen sonuçlar, zayıf asitlerin kombinasyonlarının antifungal etkinliği artırabileceğini ve belirli kombinasyonların sinerjik etkilere sahip olduğunu ortaya koymuştur. Zayıf asitlerin inhibisyon etkileri daha önce araştırılmış olsa da (Alexandre vd., 1996; Hazan vd., 2004; Legras vd., 2011; Jarboe vd., 2011), bunların $S$. cerevisiae hücrelerine karş1 kombinasyonlarının etkileri daha önce gösterilmemiştir. $\mathrm{Bu}$ nedenle, ilgili asitlerin çeşitli konsantrasyonlardaki kombinasyonları hazırlanmış ve hücrelerin maruziyet durumundaki canlılıkları Tablo 3 'de ifade edilmiştir (Tablo 3).

Elde edilen sonuçlar, zayıf asitlerin maya inhibisyonunu, daha düşük konsantrasyonların kombinasyonları ile başarabileceğini göstermiştir. Genel olarak, yağ asitlerinin birbirleri ile kombinasyonlarının bunların benzoik asit ile olan kombinasyonlarına göre daha etkin olduğu (Tablo 3b ile Tablo 3e ve 3f'nin karşılaştırılması) gözlemlenmiştir. Özellikle de oktanoik asit ve dekanoik asit kombinasyonlarının $S$. cerevisiae hücrelerine karşı daha etkin oldukları ifade edilebilir.

\section{Sonuç}

Zayıf organik asitlerle maya hücrelerinin inhibisyonunun yalnızca asitlikle ile ilişkili olmadığı gösterilmiştir. Daha da önemlisi, kombinasyon halinde zayıf asitlerin kullanılması, antifungal kimyasallar olarak bunların kullanım potansiyellerini arttırır ve koruyucular olarak ise daha az miktarda daha etkin kullanımlarını sağlar. Çalışma ile elde edilen sonuçlar, $S$. cerevisiae hücrelerine karşı zayıf asitlerin etki mekanizmaları hakkındaki bilgimizi zenginleştirmekte ve gıda, kozmetik ve ilaç endüstrisinde kullanımlarının artmasına yardımcı olacaktır. 
Tablo 3. S. cerevisiae hücrelerine karşı zayıf asitlerin sinerjik etkileri. Çözünürlüğü artırmak için zayıf asitler DMSO ile karıştırılmıştır.

Table 3. Synergistic effects of weak acids against $S$. cerevisiae cells. Weak acids were mixed with DMSO to increase solubility.

\begin{tabular}{|c|c|c|c|c|c|c|c|c|c|c|c|c|c|}
\hline \multirow[t]{2}{*}{ a) } & \multicolumn{6}{|c|}{ Hekzanoik Asit } & d) & \multicolumn{6}{|c|}{ Benzoik Asit } \\
\hline & $\mathbf{m M}$ & 0 & 1 & 2 & 4 & 8 & & $\mathbf{m M}$ & 0 & 1 & 2 & 4 & 8 \\
\hline \multirow{4}{*}{ 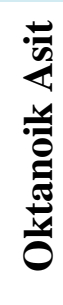 } & 0 & + & + & + & + & - & \multirow{5}{*}{ 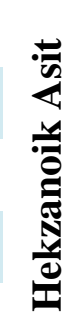 } & 0 & + & + & + & + & - \\
\hline & 0.5 & + & + & + & - & - & & 1 & + & + & + & + & - \\
\hline & 1 & + & + & - & - & - & & 2 & + & + & + & - & - \\
\hline & 2,5 & - & - & - & - & - & & 4 & + & + & - & - & - \\
\hline & & & & & & & & 8 & - & - & - & - & - \\
\hline
\end{tabular}

b)

Oktanoik Asit

\begin{tabular}{|c|c|c|c|c|c|c|}
\hline & $\mathbf{m M}$ & 0 & 0.5 & 1 & 1.5 & 2.5 \\
\hline \multirow{4}{*}{ 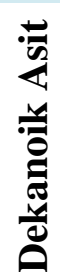 } & 0 & + & + & + & + & - \\
\hline & 0.1 & + & + & + & - & - \\
\hline & 0.2 & + & - & - & - & - \\
\hline & 0.3 & - & - & - & - & - \\
\hline
\end{tabular}

e) c)

\begin{tabular}{|c|c|c|c|c|c|c|}
\hline & $\mathbf{m M}$ & 0 & 1 & 2 & 4 & 8 \\
\hline \multirow{4}{*}{ 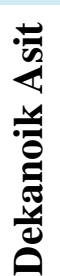 } & 0 & + & + & + & + & - \\
\hline & 0.1 & + & + & + & + & - \\
\hline & 0.2 & + & + & + & - & - \\
\hline & 0.3 & - & - & - & - & - \\
\hline
\end{tabular}

f)

\begin{tabular}{|c|c|c|c|c|c|c|}
\hline & $\mathbf{m M}$ & 0 & 1 & 2 & 4 & 8 \\
\hline \multirow{4}{*}{ 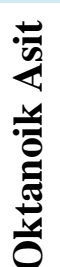 } & 0 & + & + & + & + & - \\
\hline & 0.5 & + & + & + & + & - \\
\hline & 1 & + & + & - & - & - \\
\hline & 2.5 & - & - & - & - & - \\
\hline
\end{tabular}

\section{Kaynaklar}

Alexandre, H., Mathieu, B., Charpentier, C. (1996). Alteration in membrane fluidity and lipid composition, and modulation of H+-ATPase activity in Saccharomyces cerevisiae caused by decanoic acid. Microbiology, 142(3):469-475.

Bauer, A., Kirby, W., Sherris, J.C., Turck, M. (1966). Antibiotic susceptibility testing by a standardized single disk method. American Journal of Clinical Pathology, 45(7):493.

Bracey, D., Holyoak, C., Coote, P. (1998). Comparison of the inhibitory effect of sorbic acid and amphotericin B on Saccharomyces cerevisiae: is growth inhibition dependent on reduced intracellular $\mathrm{pH}$ ? Journal of Applied Microbiology, 85(6):1056-1066.
Bergsson, G., Arnfinnsson, J., Steingrímsson, Ó., Thormar, H. (2001). In vitro killing of Candida albicans by fatty acids and monoglycerides. Antimicrobial Agents and Chemotherapy, 45(11):32093212.

Cabral, M.G., Viegas, C.A., Sá-Correia, I. (2001). Mechanisms underlying the acquisition of resistance to octanoic-acid-induced-death following exposure of Saccharomyces cerevisiae to mild stress imposed by octanoic acid or ethanol. Archives of Microbiology, 75(4):301-307.

Gášková, DI., Plášek, J., Zahumenský, J., Benešová, I., Buriánková, L., Sigler, K. (2013). Alcohols are inhibitors of Saccharomyces cerevisiae multidrugresistance pumps Pdr5p and Snq2p. FEMS Yeast Research, 13(8):782-795. 
Hatzixanthis, KI., Mollapour, M., Seymour, I., Bauer, BE., Krapf, G., Schüller, C., Kuchler, K., Piper, PW. (2003). Moderately lipophilic carboxylate compounds are the selective inducers of the Saccharomyces cerevisiae Pdr12p ATP-binding cassette transporter. Yeast, 20(7):575-585.

Hazan, R., Levine, A., Abeliovich, H. (2004). Benzoic acid, a weak organic acid food preservative, exerts specific effects on intracellular membrane trafficking pathways in Saccharomyces cerevisiae. Applied and Environmental Microbiology, 70(8):4449-4457.

Holyoak, CD., Bracey, D., Piper, PW., Kuchler, K., Coote, PJ. (1999). The Saccharomyces cerevisiae weak-acid-inducible ABC transporter Pdr12 transports fluorescein and preservative anions from the cytosol by an energy-dependent mechanism. Journal of Bacteriology, 181(15):4644-4652.

Jarboe, LR., Liu, P., Royce, LA. (2011). Engineering inhibitor tolerance for the production of biorenewable fuels and chemicals. Current Opinion in Chemical Engineering, 1(1): 38-42.

Kumar, A., Singh, S., Jain, S., Kumar, P. (2011). Synthesis, antimicrobial evaluation, QSAR and in silico admet studies of decanoic acid derivatives. Act Pol Pharm, 68:191-204.

Kumar Tyagi A., Bukvicki, D., Gottardi, D., Tabanelli, G., Montanari, C., Malik, A., Guerzoni, ME. (2014). Eucalyptus essential oil as a natural food preservative: in vivo and in vitro antiyeast potential. BioMed Research International,2014:1-9.

Lambert, R. and Stratford, M. (1999). Weak-acid preservatives: modelling microbial inhibition and response. Journal of Applied Microbiology, 86(1):157164.

Legras, JL., Erny, C., Le, Jeune, C., Lollier M., Adolphe, Y., Demuyter, C., Delobel, P., Blondin, B., Karst, F. (2011). Activation of two different resistance mechanisms in Saccharomyces cerevisiae upon exposure to octanoic and decanoic acids. Applied and Environmental Microbiology, 76(22):7526-7535.

Mollapour, M., Phelan, JP., Millson, S.H., Piper, PW., Cooke, FT. (2006). Weak acid and alkali stress regulate phosphatidylinositol bisphosphate synthesis in Saccharomyces cerevisiae. Biochemical Journal, 395(1):73-80.

Papadimitriou, MN., Resende, C., Kuchler, K., Brul, S. (2007). High Pdr12 levels in spoilage yeast (Saccharomyces cerevisiae) correlate directly with sorbic acid levels in the culture medium but are not sufficient to provide cells with acquired resistance to the food preservative. International Journal of Food Microbiology, 113(2):173-179.

Rattanachaikunsopon, P., and Phumkhachorn, P. (2010). Lactic acid bacteria: their antimicrobial compounds and their uses in food production. Annals of Biological Research, 1(4):218-228.

Tenreiro, S., Nunes, PcA., Viegas, CA., Neves, MS., Teixeira, MC., Cabral, MG., Sá-Correia, I. (2002). AQR1 gene (ORF YNL065w) encodes a plasma membrane transporter of the major facilitator superfamily that confers resistance to short-chain monocarboxylic acids and quinidine in Saccharomyces cerevisiae. Biochemical and Biophysical Research Communications, 292(3):741-748.

Ullah, A., Orij, R., Brul, S., Smits, GJ. (2012). Quantitative analysis of the modes of growth inhibition by weak organic acids in Saccharomyces cerevisiae. Applied and Environmental Microbiology, 78(23):83778387.

Viegas, CA., Rosa, MF., Sá-Correia, I., Novais, JM. (1989). Inhibition of yeast growth by octanoic and decanoic acids produced during ethanolic fermentation. Applied and Environmental Microbiology, 55(1):21-2.

Viegas, CA., Sá-Correia, I. (1997). Effects of low temperatures (9-33 C) and $\mathrm{pH}(3.3-5.7)$ in the loss of Saccharomyces cerevisiae viability by combining lethal concentrations of ethanol with octanoic and decanoic acids. International Journal of Food Microbiology, 34(3):267-277.

Wang, Y., Zeng, X., Zhou, Z., Xinga, K., Tessema, A., Zeng, H., Tian, J. (2015). Inhibitory effect of nerol against Aspergillus niger on grapes through a membrane lesion mechanism. Food Control, 55:54-61. 